Indian J Pediatr 1991; 58 : 407-414

\title{
Rural Health Services
}

\author{
Suneeta Mukherjee \\ Ministry of Health \& Family Welfare, Government of India
}

India is a signatory to the Alma Ata declaration (1978) and is committed to attaining the goal of Health for All by the year 2000 A.D. through primary health care approach. Since independence, efforts have been made for development of rural health infrastructure to cater to the rural population which covers over $70 \%$ of our population.

The structure is based on directions provided by "Health Survey and Development Committee" (Bhore Committee, 1946). The committee recognised the inter-sectoral efforts required to provide basic health services to the community. The community development programme launched on 2 nd October, 1952 was the first integrated rural development programme with health as one of its major components for all-round development of rural areas. One primary health centre with three sub-centres for every community development block covering a population of 60,000 was planned. Improvements were suggested by the Health Survey and Planning Committee (Mudaliar committee) in 1961. In 1963, Government of India adopted the "extension approach" and integration of $\mathrm{MCH}$ services with family planning programme. One uni-purpose field worker was provided for every 20,000

Reprint requests : Dr. Suneeta Mukherjee, Joint Secretary, Ministry of Health and Family Welfare, New Delhi-110 001. rural population and a block extension educator for every primary health centre. A sub-centre for every 10,000 population with a trained auxiliary nurse midwife and one lady health visitor for four sub-centres was provided.

On the recommendations of "Committee on integration of health, family planning and $\mathrm{MCH}$ (Kartar Singh Committee, 1973)", the Government decided to have an integrated approach for delivery of health services by progressively introducing multipurpose health workers and supervisors.

The 5th five year plan laid stress on the existing uni-purpose workers being trained and re-oriented in the multi-purpose approach. The minimum needs programme consisted of establishment of one primary health centre (PHC) for each community development block, one sub-centre for every 10,000 population and buildings for primary health centres and sub-centres. Out of every 4 PHCs, one was to be converted into a 30 bedded rural hospital to be known as community health centre by adding specialised services in surgery, pediatrics, medicine, obstetrics and gynecology.

In 1978, India signed Alma Ata declaration. National health policy of India was evolved in 1983. It laid down restructuring of the health services with the approach of establishing a well dispersed network of comprehensive health care services 
integrally linked with extension and education approach which could be performed by well trained volunteers, auxiliaries and para-medical workers. Transfer of knowledge of simple skills and technologies to health volunteers was envisaged. Decentralization of primary health care system with active community participation having adequate support of secondary and tertiary level was aimed at. The strategy and plan of action for achieving the goals of Health for All was laid down specifically during the VIth plan and implemented in the VIth and VIIth plans.

The objective of rural health services is to provide primary health care to the rural population. Primary health care is the first level of contact which an individual has with the national health system bringing health care to the people's abode. A pyramid like infrastructure has been established to cover the rural areas in the country. These consist of sub-centres, primary health centres and community health centres.

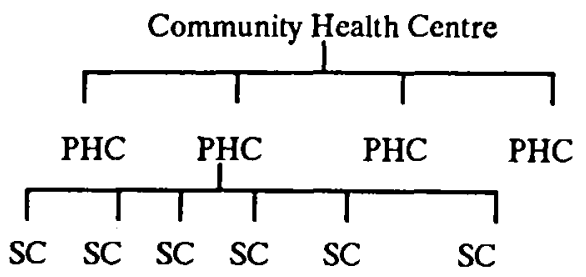

\section{SUB-CENTRES}

A sub-centre has been established to cover 5,000 population in normal areas and 3,000 population in hilly, tribal and backward areas. Each sub-centre is to be manned by an A.N.M. (auxiliary nurse midwife) who is funded by the central government and a male health worker who is supposed to be funded by the state government. It covers 4 5 villages. The pattern of assistance is as follows :

\author{
Non-recurring: Rs. 3200/- (towards equip- \\ ment and furniture) \\ Recurring \\ Salary of ANM As per state pay scales \& \\ allowances \\ Helper Rs. 600 p.a. \\ Contingency Rs. 600 p.a. \\ Rent (if sub- \\ centre is in \\ rented building) Rs. 1000 p.a. \\ Medicines Rs. 2000 p.a. \\ Salary of L.H.V. As per state pay scales \& \\ allowances
}

The functions of a sub-centre : Treatment of minor ailments; first aid for accidents and emergencies; ante-natal, natal and post-natal services; health education; motivation for family planning and distribution of conventional contraceptives; Immunization services; prophylaxis against vitamin $\mathrm{A}$ deficiencies and anaemia; reporting of occurrences of epidemics; and collection of blood slides.

It is clear that the sub-centres cater to the minimum health and family welfare services including epidemics, immunisation, first aid and minor ailments. A Register of eligible couples for family welfare is maintained at each sub-centre and family welfare services (non-surgical) are available.

There is also one L.H.V. to supervise every six sub-centres.

\section{PRIMARY HEALTH CENTRES}

The next level is the primary health centre which covers 30,000 population in generál and 20,000 in hilly, tribal and backward areas. It is manned by a medical officer and other para-professional and para-medical staff. It generally covers about six subcentres and is funded by the state sector under the minimum needs programme. 
Some states have two medical officers posted under primary health centre. PHC is expected to have some essential equipment for life saving. A simple laboratory with a microscope and reagents are available. Two to four observation beds are there in a PHC. About $50 \%$ of them are in Government buildings. Essential drugs are expected to be available with the PHCs.

The PHC maintains some basic records which are intended to prove an effective tool to built up health management informations systems. At present, printed registers are being made use of with coded formats in certain areas.

It is attempted to provide a vehicle in running condition with POL of Rs. 15,000 (petrol run vehicle) \& Rs. 9,500 (for diesel run vehicles). The working group report of the planning commission on VIIIth plan has recommended this to be increased from Rs. 20,000 to Rs. 60,000 as it was found to be totally inadequate. Loans to purchase vehicles to functionaries and fixed travelling allowance is also recommended by the working group on VIIIth plan.

The functions of primary health centre include :

1. Availability/insertion of family welfare services, Nirodh, oral pills and IUD.

2. Boosting national health programmes like nutritional programmes to prevent and treat diseases like malaria, filaria, tuberculosis, leprosy, blindness, diarrheal diseases and nutritional deficiencies.

3. Drugs supplied under centrally sponsored programmes like oral dehydration salt (ORS), packets and other nutritional supplements like vitamin ' $A$ ', iron and folic acid tablets.

4. Education of hygienic disposal of waste and storage.
5. Health education in order to reduce morbidity and mortality due to preventable diseases like diarrhoea, dreadful diseases e.g., tetanus, diphtheria, whooping-cough, poliomyelitis, measles, tuberculosis and many other nutritional diseases.

6. Testing for laboratory diagnosis of diseases like malaria, tuberculosis, leprosy.

\section{COMMUNITY HEALTH CENTRES}

Community heath centres covers 1 lakh population and 80,000 population in difficult and hilly areas. This unit functions as a referral hospital to the $\mathrm{PHC}$ and gives preventive, promotive and curative services. There are 4 specialities namely medicine, surgery, pediatrics and gynaecology with 30 indoor beds and facilities for good laboratory and radiologic services.

The functions include : regular out-patient services; in-patient services ( 30 beds); comprehensive family welfare services i.e. surgical \& non-surgical; specialist services including labour room services; surgical services; specialist medical services e.g. pediatrics; laboratory facilities for testing; $X$ ray for diagnostic facilities; supply of drugs under various national health programmes; and maternal, child health and immunisation services.

One vehicle at present is available at CHC level with the same fixed POL \& maintenance as in PHC. The working group on VIIIth plan has recommended one ambulance and two vehicles for staff including mobility van and a vehicle for preventive and promotive activities. This would cover supervision and implementation of national health and family welfare programmes.

Information flows from PHCs to district CMO who maintains data for planning, programming, implementation and evaluation of various health programmes. 


\section{SUB-DISTRICT AND DISTRICT HOSPITALS}

The referral from CHC is sub-district hospital where there are indoor facilities and more specialities e.g. ophthalmology, anesthesiology and dental surgery and also more diagnostic facilities such as electrocardiography. $A$ well equipped labour room and operation theatre are other requirements at a sub-district level hospital. In a district hospiial, the additional specialities like clinical pathology, psychiatry, pediatrics, E.N.T. are also there. A school of nursing is generally available and also a trained medical records officer. However, most of the sub-district and district hospitals would not be counted for health care in the rural areas as they would be located in municipal areas.

The position of setting up the rural health services infrastructure is summarized in Table 1.

There are various problems which are seen in the functioning of the infrastructure. The sub-centre is the peripheral level of institutionalised rural health services. While most of the sub-centres have been opened, many of the ANMs do not stay in the subcentres. The basic qualification of the ANM is 10 th pass and she was to be selected from the local area and given a training of 18 months. However, even after selection, it is seen that she prefers to get a headquarter posting or urban area posting and does not like to live in villages due to husband's posting, children's education or better prospects. One genuine reason is that buildings have not been built everywhere. It is estimated that only $50 \%$ of the buildings have been built and the rest are to be rented out. Buildings are sometimes not available on rent. However, it is seen that even where buildings have been built, ANMs are not staying in the building that is built. They are also not always following their visit schedules and keeping up-dated records. Many states have not posted their male counterparts with the result that the scheme is not fully functional and the working is thus incomplete.

The primary health centres and the community health centres are budgeted by the state government and a gap remains between the target and achievements. Since these are funded by the state governments through the minimum needs programme, the central government gets involved mainly at monitoring level. However, even the subcentres which were to be established with the central government funds could not be opened in 1990-91 as per the targets (4765) due to paucity of funds.

TABLE 1. Status of Rural Health Services Infrastructure

\begin{tabular}{lcccc}
\hline Catcgory & $\begin{array}{c}\text { Total No. } \\
\text { required by } \\
1.4 .90\end{array}$ & $\begin{array}{c}\text { No. in position } \\
\text { as on } 1.4 .90\end{array}$ & $\begin{array}{c}\text { Target } \\
1990-91\end{array}$ & Achievement \\
\hline Sub-centre & $1,37,000$ & $1,30,390$ & 4877 & 143 \\
Primary health centre & 23,097 & 20,537 & 1396 & 3 \\
$\begin{array}{l}\text { Community } \\
\text { health centre }\end{array}$ & 2,282 & 1,855 & 285 & 7 \\
\hline
\end{tabular}




\section{GRASSROOT LEVEL VOLUNTEERS/ WORKERS}

In addition to institutionalised training centres, we have individuals working at grassroot level who are not whole-time workers or government servants. There are the traditional bith attendants (TBA) in each village who get some nominal amount (Rs. 3 for each reported delivery case). The dias are to be trained and provided with dai kits which are sterilised to ensure safe delivery. The main aim is to ensure safe delivery and reduce maternal mortality rate and infant mortality rate.

One major functionary which was provided for every 1,000 population in the year 1977 was the village health guide. It was a $100 \%$ sponsored scheme and an honorarium of Rs. 50 p.m. along with the medical kit of the same amount was to be given to the health guides who were basically volunteers. The VHG was meant to be a link between the community and health functionaries and provide the primary health care services. The scheme underwent change in 1981 when it was decided to have a scheme at $50 \%$ centrally sponsored and $50 \%$ by the states. However, these orders were later withdrawn. In 1986, it was again decided to recruit only women volunteers. VHG from some states have gone to law courts and the scheme stands still then. The present position is that the VHGs wherever they are, are getting Rs. 50/- p.m. as honorarium without the kit or training. It is realised at various levels that the scheme needs to be revamped but a large sum of money is required which is not readily available.

\section{TRAINING}

Training is an essential component of rural health services. This covers initial basic training to impart skills \& education and later in-service or refresher training to update skills.

\section{Basic Training Programmes}

(i) Health worker (female) training programme. There are 473 ANM training centres, 348 government and 125 voluntary, with an annual admission capacity of 21,548. Health worker (female) training schools are $100 \%$ centrally sponsored under family welfare programme. The duration of the training is one and a half years and the minimum qualification required for admission to this course is 10 th pass. There are 4 to 5 teachers in each school. The quality of the training of ANM's (Female Health Worker) needs improvement in terms of availability of teaching staff, physical facilitics and audio-visual aids. There is no periodic continuing education training programmes for the teachers of ANM school to update their knowledge and skills in different national health \& family welfare programmes.

TABLE 2. Dais and VHGs in Position

\begin{tabular}{lcccc}
\hline Category & $\begin{array}{c}\text { Total No. } \\
\text { required by } \\
1.4 .90\end{array}$ & $\begin{array}{c}\text { No. in position } \\
\text { as on } 1.4 .90\end{array}$ & $\begin{array}{c}\text { Target } \\
1990-91\end{array}$ & Achievement \\
\hline Dais & $5,88,651$ & $5,92,923$ & 10,000 & 393 \\
Village Health Guides & $5,88,651$ & $3,37,014$ & - & - \\
\hline
\end{tabular}


During the VIIIth plan, efforts will be made to improve the quality of training imparted in their training institutions.

Health worker (male) training programme. It is also a centrally sponsored scheme under family welfare programme. Basic training of one year is imparted to persons with minimum qualification of 10 th pass. At present, 72 training schools are working in the country which include 44 health \& family welfare training centres. The total admission capacity is 4,320. The scheme is in operation from 1982 onwards. As the employment of health worker (male) is in the state sector, the states are hesitant to continue the training programmes. From time to time, efforts are made to impress the state governments to the need of training health workers (male) so that the sub-centre is made fully functional.

\section{In-Service Training Programme}

1. Female health assistant (lady health visitors) training progranme. Senior female health worker with 5 years of experience are given 6 months promotional training to become health assistants (female lady health visitors). At present, there are 46 promotional schools with an annual admission capacity of 3,206 which are functioning in the country. It is also a $100 \%$ centrally sponsored scheme under family welfare.

Health assistant (male) training programme. At present, there is no shortage of male health assistants in the country, as a result schools for training of male health worker for training to become male health assistant has not been taken up.

Orientiation training of medical \& paramedical personnel. It is a centrally sponsored scheme under family welfare. It was started with the objectives to train medical and para-medical personnel working at PHCs and sub-centres including their trainers. The categories covered under the scheme consist of MO(PHC), HA(M) and $\mathrm{HA}(\mathrm{F}), \mathrm{HW}(\mathrm{M})$ and $\mathrm{HW}(\mathrm{F})$ and key trainers. Functionaries of each category are to be imparted training in the same institution where they had their basic training. The duration of the training is two weeks.

The financial assistance admissible under the scheme is in the form of $100 \%$ nonrecurring grant towards hostel for 20 trainces along with lecture and demonstration room, furniture for hostel and class room, kitchen articles, training equipment and aids. The recurring grant is admissible on 50 : 50 sharing basis between the Government of India and state government and the components covered under this scheme are : rent for hostel till building is completed, contingency, consumable training material, additional teaching staff, staff for hostel and class rooms and stipened. These are approved for all the states. Regarding UTs as they do not have enough training facilities available with them, they will seek the assistance of adjoining states to train their personnel. This scheme has replaced training and employment of MPW (male) scheme which was launched in 1974.

\section{Laboratory Facilities at PHCs and Rural Dispensaries}

It is a centrally sponsored health scheme. Under the scheme, financial assistance is made available to the states for setting up of laboratories at primary health centres catering to 30,000 population, so as to enable them to carry out routine investigations and diagnose diseases covered under national health programme. The Government of India provides the facility in the form of 
equipments including microscope, laboratory reagents and glass-ware. The post of laboratory technician is provided by the state government under the state sector minimum needs programme.

\section{Health \& Family Welfare Training Centres (H \& FWTCs)}

These training centres were set up under the family welfare programme with $100 \%$ financial assistance by the central government to undertake in-service training programme for health functionaries working in the field for delivery of primary health care services.

Initially, the $H$ \& FWTCs were training staff under family planning programme but from 1974 onwards when multipurpose workers' scheme was launched in the country, they also took up the training of medical officers and unipurpose workers under the multipurpose workers' scheme. These training centres provide in-service job-oriented training to all the health functionaries working at the block level and below. The $47 \mathrm{H}$ \& FWTCs are distributed all over the country.

The following training programmes are taken by H \& FWTCs from the year 1990 . 91 onwards :

\begin{tabular}{lcc}
\hline $\begin{array}{l}\text { Name of the } \\
\text { course }\end{array}$ & Duration & Number \\
\hline $\begin{array}{l}\text { Medical officers } \\
\text { Health assistant } \\
\text { (Male \& Female) }\end{array}$ & $2 \mathrm{wk}$ & 3 \\
$\begin{array}{l}\text { ANMTCs \& Male } \\
\text { training faculty }\end{array}$ & $2 \mathrm{wk}$ & 3 \\
$\begin{array}{l}\text { Block extension } \\
\text { educators }\end{array}$ & $2 \mathrm{wk}$ & 2 \\
\hline
\end{tabular}

There were other schemes which were conceived as promotional/additional qualification of primary health care staff, training community health officers \& scheme of specialists and para-medical which could not continue beyond 1990-91 due to various reasons.

\section{IMPACT OF THE SERVICE}

With the expansion of infrastructure in the country, much has been achieved. The death rate has come down from 15 per thousand in 1976 to 10.2 in 1989. The birth rate has come down from 34.4 in 1976 to 30.5 in 1989. The infant mortality rate has come down from 129 in 1976 to 91 in 1989. The incidence of communicable diseases has also shown a marked reduction. The incidence of malaria has come down by $71.25 \%$ since 1976 . By the end of 1986 , a total number of 3.06 million cases of leprosy have been under treatment. There were nearly 1.24 million cases of tuberculosis under treatment by 1986 . It is estimated that uptil now, 120 million births have been averted due to implementation of family welfare programme. The expectancy of life at birth in 1986 to 1991 was estimated to be 58.1 for males and 59.1 years for females.

The recommendations of the working group of the planning commission under VIIIth plan have been referred to and discussed about wherever relevant. The main thrust during VIIIth plan would be consolidation of the infrastructure established during the VIth and VIIth plan. The subcentres, PHCs and CHCs need to be increased in number but what is most important is that they have to be operationalised. The dais have to be trained and to be provided with pre-sterilised disposable sterilised kits. All the functionaries working in the rural areas need to be trained in media, 
in communication skills to provide basic health and family welfare education to the masses at large. The village health guides scheme needs to be rejuvenated and made functional. It is necessary during the VIIIth plan to create demand generation for health and family welfare particularly family wel- fare schemes. The public must demand family welfare services like they demand ration, atta or sugar. The health and family welfare programme must become a people's movement without which the national development itself is getting confined.

\section{SUDDEN RESPIRATORY ARREST IN ASTHMA}

The rates of mortality from asthma are increasing in many countries. Of particular interest are reports describing rapid decompensation leading to respiratory arrest, sudden death or both in young patients with otherwise stable asthma. Risk factors for this include liability of the lower airways, lack of appreciation of the severity of airflow obstruction on the part of primary care physicians, and psychological factors, including emotional instability, depressive symptoms, and family dysfunction. The authors evaluated the occurrence of these episodes in relation to the peak outdoor mold sporulation season. Ten of the 11 patients with asthma who had respiratory arrest (91 percent) had positive skinpuncture tests for sensitivity to alternaria, as compared with 31 percent of the controls ( $P$ $<0.001$ ), and the serum lcvels of IgE antibodies to alternaria were elevated in all 9 patients tested. Exposure to the aeroallergen $A$. altemata is a risk factor for respiratory arrest in children and young adults with asthma. 